\title{
The M5.0 Suining-Tongnan (China) earthquake of 31 January 2010: A destructive earthquake occurring in sedimentary cover
}

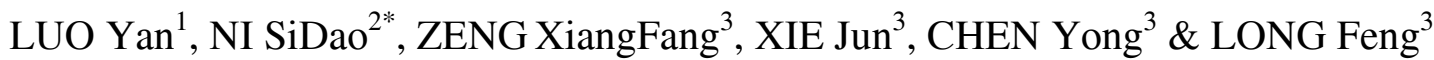 \\ ${ }^{1}$ Institute of Earthquake Science, China Earthquake Administration, Beijing 100036, China; \\ ${ }^{2}$ Institute of Geodesy and Geophysics, Chinese Academy of Sciences, Wuhan 430077, China; \\ ${ }^{3}$ Menghcheng National Geophysical Observatory, School of Earth and Space Sciences, University of Science of China, Hefei 230026, China
}

Received June 23, 2010; accepted November 9, 2010

\begin{abstract}
Usually, only crystalline basement is strong enough to store the massive strain energy that can be released in a damaging earthquake. By contrast, sedimentary cover is weak, because of its relatively high porosity and fluids. Therefore, it generally cannot accumulate enough energy for strong earthquakes. On January 31, 2010, a M5.0 earthquake occurred near the border of Suining and Tongnan in China. It excited strong short-period Rayleigh waves $\mathrm{Rg}$, indicative of its shallow focal depth. The focal depth is constrained to less than $4 \mathrm{~km}$, most probably in the range of $1-3 \mathrm{~km}$, by modeling amplitude dependence on the frequency and waveforms of teleseismic depth phases (pP, sP). Because the local Mesozoic sedimentary cover is about $6 \mathrm{~km}$ thick, this earthquake should have occurred in the sedimentary cover. Though some shallow earthquakes with magnitudes up to M4 occur in Paleozoic sediments, this earthquake is the first M5 event studied in Mesozoic sedimentary cover. This event provides a rare opportunity to study seismogenic processes of damaging earthquakes in sedimentary basins.
\end{abstract}

Suining-Tongnan Earthquake, sedimentary cover, damaging earthquake

Citation: $\quad$ Luo Y, Ni S D, Zeng X F, et al. The M5.0 Suining-Tongnan (China) earthquake of 31 January 2010: A destructive earthquake occurring in sedimentary cover. Chinese Sci Bull, 2011, 56: 521-525, doi: 10.1007/s11434-010-4276-2

Most strong earthquakes occur at inter-plate boundaries, with much less frequent damaging earthquakes occurring within stable plates [1]. For example, since 1941, three M6+ earthquakes (with the strongest having a magnitude as great as M7.1) have struck the Yilgarn Craton in Western Australia, one of the oldest cratons in the world (http://www. seismicity.see.uwa.edu.au/welcome/seismicity_of_western_ australia/wa_historical). India, another stable geological unit, also suffered substantial loss from the 1993 Latur and 2001 Gujarat earthquakes. Previous studies have found that the distribution of focal depths for events in stable continental events shows a bimodal pattern, with most events in two seismogenic layers, the upper one third of the crust and the lower one third of the crust, with M4.5-8 earthquakes predominantly occurring with a depth less than $7 \mathrm{~km}$ [2].

*Corresponding author (email: sdni@ustc.edu.cn)
There are many earthquakes that have occurred at depths less than $5 \mathrm{~km}$ (and perhaps as shallow as $1 \mathrm{~km}$ ) in both southwestern Australia [3] and the Lake Ontario region of North America [4,5]. Recently, a study of the aftershock sequence of the 2008 Great Wenchuan earthquake also reported events shallower than $5 \mathrm{~km}$ in the northeastern tip of the Wenchuan earthquake rupture zone [6]. All these shallow earthquakes took place in the rigid rocks of Paleozoic strata or plutonic bodies, both of which are very strong and accumulate massive strain energy. Large stress associated with the strain can only exceed the strength of the shallow part of the crust and cannot overcome the strength of the deeper part of the crust. Therefore, shallow earthquakes occur in stable continental regions [3]. Note that there is a very limited number of reports of damaging earthquakes in sedimentary cover. For example, an M4.2 earthquake that occurred in Kentucky at a depth of $1.7 \mathrm{~km}$ is believed to 
have occurred in the Paleozoic cover [7].

The Sichuan Basin is a rigid stable block surrounded by mountain belts. Situated in the center of the Sichuan Basin, the Suining-Tongnan area experiences very low seismicity with historical earthquakes generally less than M3. However, a M5.0 earthquake struck this area on January 31, 2010, leading to one fatality and 12 injuries in addition to the economic loss of tens of millions of dollars. Because of the low seismicity, this area is only covered with a sparse seismograph network. Therefore it is very difficult to determine accurate focal depths with travel times. Typically, a dense network is needed for high-resolution focal depth determinations if only travel times are used. For example, the closest station ideally should be closer than 1.4 times the focal depth [8]. However, the closest station for the Suining-Tongnan event is more than $80 \mathrm{~km}$ away, and therefore other methods are necessary to reliably determine focal depth. The focal depth solution from the China Seismic Network Center is $10 \mathrm{~km}$ (www.csndmc.ac.cn), which is not consistent with well-developed short period (1-2 s) Rayleigh waves $\mathrm{Rg}$. The $\mathrm{Rg}$ is strongly dispersive, indicating a low shear velocity in the top few kilometers of the crust. Moreover, $\mathrm{Rg}$ is much stronger than the corresponding body waves, suggesting a depth less than $4 \mathrm{~km}$ [9]. After comparing data with synthetic seismograms at regional distances (to examine amplitude dependence on frequency) and at teleseismic distances (depth phases $\mathrm{pP}$ and $\mathrm{sP}$ ), we confirm that the hypocenter of the event is shallower than 4 $\mathrm{km}$ and very probably shallower than $2.5 \mathrm{~km}$.

This event occurred in a gas field within the SuiningTongnan area, where the sedimentary cover is about $5-7 \mathrm{~km}$ thick [10-12]. The gas field is situated in the center of the Sichuan Basin, where Archean to Jurassic sedimentary strata are well developed. Prior to the middle Triassic, the sedimentary rocks are of marine origin, and then transgress into terrestrial deposition in the late Triassic. The Jurassic strata formed from lake deposition are predominantly lacustrine $[10,11]$. The geological strata are well understood from oil wells in this area. For example, the Jialingjian group is at depth of $3 \mathrm{~km} \mathrm{[12].} \mathrm{If} \mathrm{this} \mathrm{earthquake} \mathrm{hypocenter} \mathrm{was} \mathrm{shal-}$ lower than $3 \mathrm{~km}$, it almost surely would have occurred in Triassic or younger strata. These young sedimentary rocks are porous and fluid-filled, and therefore should be weak and incapable of storing sufficient energy for damaging earthquakes, although they could trigger micro-seismicity (M2-3 or weaker). If this event indeed occurs in Mesozoic strata, it would be a very rare event, demanding more detailed studies of its seismogenic processes.

\section{Short period surface waves $\mathrm{Rg}$}

Strong Rg waves (with periods between 0.4 and $2.5 \mathrm{~s}$ ) are usually observed at distance ranges of $50-125 \mathrm{~km}$ for very shallow earthquakes and explosions [9,13-15]. In this frequency range (0.4-2.5 s periods correspond to frequencies of $0.4-2.5 \mathrm{~Hz}$ ),
$\mathrm{Rg}$ is strong only for depths less than $5 \mathrm{~km}$, with most energy in the upper $2-3 \mathrm{~km}$. Therefore, short period $\mathrm{Rg}$ are not observed for events deeper than $4 \mathrm{~km}$. Kafka [9] and Bath [16] proposed that clear $\mathrm{Rg}$ is a reliable indicator of shallow earthquakes.

The Suining-Tongnan earthquake excited strong Rg waves at most stations in the Sichuan and Chongqing seismic networks (Figure 1). As mentioned, the stations in this region are sparse because of low historical seismicity with the closest station located at least $80 \mathrm{~km}$ away from the earthquake. This limits the possibility of reliable focal depth calculations from travel times alone. Instead, waveform modeling techniques should be used to constrain focal depth.

Indeed, strong Rg waves are observed on many stations inside the Sichuan Basin, indicating that the event is shallow (Figure 2). Because of the low shear velocities in the shallow part of Sichuan Basin, the Rg waves show dramatic dispersion, with shorter period waves lagging longer period waves. Because the amplitude of Rayleigh waves decays exponentially with depth, shallower earthquakes generate stronger short period Rayleigh waves. And because of the lower group velocity of the short period waves, the amplitude of later-arriving short period wave trains are stronger than that of former-arriving long period wave trains excited by shallow earthquakes.

Although short period $\mathrm{Rg}$ provides qualitative evidence for focal depths less than $4 \mathrm{~km}$, depths can be more quantitatively constrained with waveform modeling. We investigate the Rg amplitude dependence on frequency with synthetic seismograms computed with the FK method [17]. We adopted a velocity model by Wan et al. [18] who developed a finite-frequency inversion algorithm for reliable $1 \mathrm{D}$ velocity profiles. Earthquake source parameters are inverted from waveforms, and a fault plane solution shows the thrust mechanism (strike $15^{\circ}$, dip $50^{\circ}$ and rake $87^{\circ}$ ). We assume that $Q_{\mathrm{s}}$ is 100 for the upper $3 \mathrm{~km}$ and 300 for deeper regions.

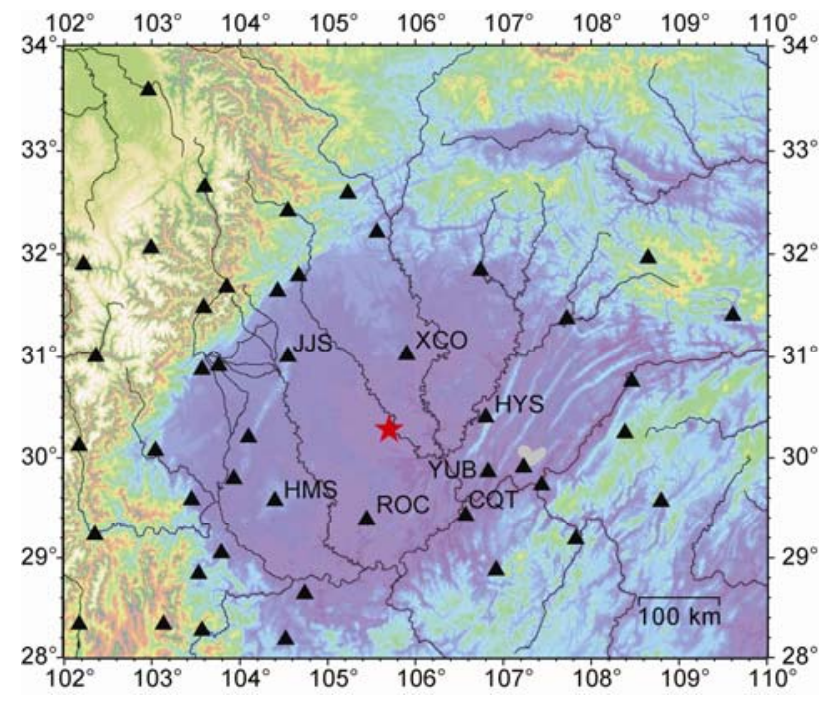

Figure 1 The Suining-Tongnan earthquake (star) and seismographic stations (triangle). The labeled stations show strong $\mathrm{Rg}$ waves. 


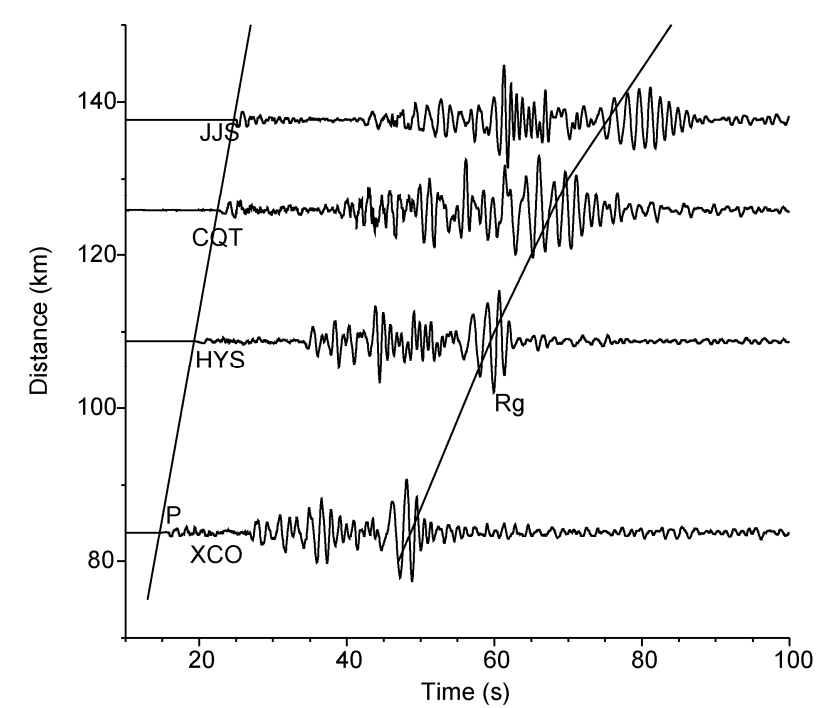

Figure 2 Record section of vertical component seismograms show strong $\mathrm{Rg}$, manifesting strong dispersion and indicating shallow depth.

From Figure 3, we observe that longer period waves (4s and longer, with arrivals at around 25-30 s) are well matched for focal depths of $4 \mathrm{~km}$, but shorter period waves (periods of around $1 \mathrm{~s}$ with arrivals near $31 \mathrm{~s}$ ) are too weak. The focal depth is set to $2.5 \mathrm{~km}$ and the whole wave trains fits well, suggesting that the $1 \mathrm{D}$ shear velocity model and the focal depth are probably appropriate for this study. If $Q_{\mathrm{s}}$ is chosen to be 50 for the upper $3 \mathrm{~km}$, a focal depth of 1.5 $\mathrm{km}$ can explain the observed waveforms. The seemingly different depths of $2.5 \mathrm{~km}$ for $Q_{\mathrm{s}}=100$ and $1.5 \mathrm{~km}$ for $Q_{\mathrm{s}}=50$ are caused by cancellation of stronger amplitudes from shallower depths and the more highly attenuated amplitude from lower $Q$. Saikia et al. [17] investigated in detail the effects of $Q$ on $\operatorname{Rg}$ amplitude, and obtained a $Q$ model for the New England region of the United States. As New England is geologically older than the Sichuan Basin, the $Q_{\text {s }}$ for the Sichuan Basin should be lower, and therefore a shallower focal depth is needed to generate strong Rg (Figure 3(b)).

In the epicentral region, no ground rupture is observed from field instigations and damage is limited in extent. Therefore, the event cannot be too shallow (i.e. $<\sim 0.5 \mathrm{~km}$ ). This is because an M5 earthquake (typically with rupture dimension of 1-3 km) would break the ground if the centroid depth was too shallow (i.e. shallower than half the rupture width). Another shallow earthquake, with a centroid depth of $320 \mathrm{~m}$, was claimed by Dawson et al. [19] to be the weakest earthquake observed with INSAR. Based on these factors, we think that the centroid depth of the SuiningTongnan earthquake is within the range of $2 \pm 1.5 \mathrm{~km}$.

Although $\mathrm{Rg}$ is a good indicator of shallow earthquakes, there are some limitation for its application. First, the crustal structure should be simple. Otherwise, 3D heterogeneity and topography would cause strong scattering or even destruction of $\mathrm{Rg}$, making it particularly challenging to identify. Second, if $Q$ is very low in the shallow crust, $\mathrm{Rg}$ can be very weak and hard to be observed at all. Third, the radiation pattern of $\mathrm{Rg}$ from tectonic earthquakes is not isotropic, which leads to an absence of $\mathrm{Rg}$ on certain paths. Therefore, the absence of $\mathrm{Rg}$ does not automatically support a deep hypocenter for the earthquake [9].

\section{Teleseismic depth phase $\mathbf{p P}$ and $\mathbf{s P}$}

To confirm that the earthquake occurred in the very shallow part of the crust, we also modeled teleseismic $\mathrm{P}$ waves. Typically, teleseismic $\mathrm{P}$ and its depth phases (pP and $\mathrm{sP}$ ) can be observed for $M_{\mathrm{w}} 5.0$ at teleseismic distances of $30^{\circ}-90^{\circ}$. Teleseismic $\mathrm{P}$ waves propagate by diving from the hypocenter, but the depth phases $\mathrm{pP}$ and $\mathrm{sP}$ form when up-going $\mathrm{P}$ and $\mathrm{S}$ waves are reflected from the free surface. Engdahl et al. [20] proposed the EHB method for locating
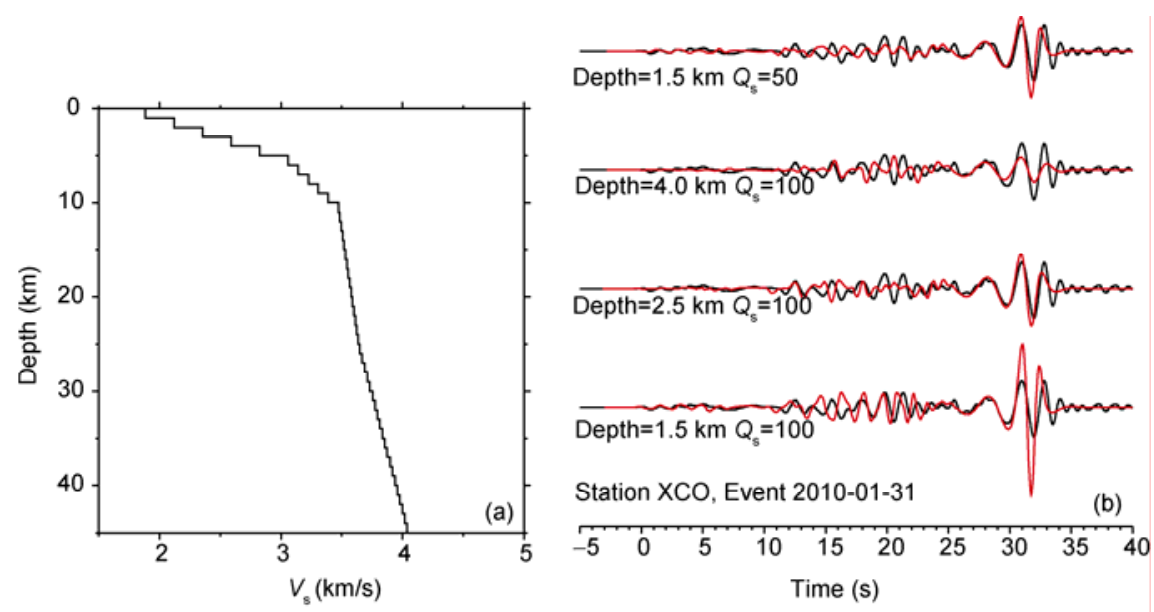

Figure 3 (a) The 1D shear velocity model from Wan et al. [18]; (b) comparison between data (black) and synthetic vertical seismograms (grey). When $Q_{\mathrm{s}}=100$ and focal depth $=1.5 \mathrm{~km}, \mathrm{Rg}$ is too strong on synthetic seismograms. But when focal depth $=4 \mathrm{~km}, \mathrm{Rg}$ is too weak. A focal depth of $2.5 \mathrm{~km}$ provides the best waveform match for $Q_{\mathrm{s}}=100$, but synthetic seismograms with $Q_{\mathrm{s}}=50$ and depth=1.5 $\mathrm{km}$ fit observation equally well. 
global earthquakes. This involves the use of multiple seismic phases including $\mathrm{P}, \mathrm{pP}$ and $\mathrm{sP}$ plus others such as $\mathrm{S}$, PKiKP, PKPdf, and pwP. As compared to locations determined from ISC and NEIC, the depth resolution of the EHB method is much higher. Because of the very close raypaths of $\mathrm{P}, \mathrm{pP}$ and $\mathrm{sP}$, the differential times of $\mathrm{pP}-\mathrm{P}$ and $\mathrm{sP}-\mathrm{P}$ are almost only sensitive to focal depth and are not affected by the velocity structure of the Earth's interior. With even a small change of focal depth, the differential times of pP-P and sP-P are changed appreciably. For example, for a $2 \mathrm{~km}$ depth change, pP-P changes by about $\sim 0.6 \mathrm{~s}$, and sP-P changes by $\sim 0.9 \mathrm{~s}$, which would be obvious on short period $\mathrm{P}$ wave records. Therefore $\mathrm{pP}$ and $\mathrm{sP}$ can be used to obtain precise focal depths.

Two high quality seismographic stations (COLA and WRAB) from GSN/IRIS were chosen for teleseismic P waveform modeling. Their epicentral distances were $69.5^{\circ}$ and $57.0^{\circ}$ respectively. Instrument responses were first removed to obtain velocity ground motion. Then a $0.7-2 \mathrm{~Hz}$ band pass filter was applied to suppress microseism signals, which were very strong in the frequency band of (0.05-0.3 $\mathrm{Hz}$ ). Focal mechanisms and velocity models are the same as those used in section 1 .

For different focal depths, we computed synthetic seismograms (red in Figure 4(b)) and compared them with observed waveforms (black in Figure 4(b)). As expected, for larger focal depths, $\mathrm{pP}$ and $\mathrm{sP}$ lag much later than $\mathrm{P}$, and when focal depth is very small $(1-2 \mathrm{~km})$, the three seismic phases $(\mathrm{P}, \mathrm{pP}$ and $\mathrm{sP})$ almost merge into one signal. Synthetic seismograms with a focal depth of $1 \mathrm{~km}$ can explain data very well for both COLA and WRAB stations. However, for depths of $4 \mathrm{~km}$ or larger, the synthetic waveforms are very different from the observed ones. Therefore, the earthquake is indeed considered to be shallower than $4 \mathrm{~km}$.

Of course, seismological datasets (teleseismic or local waveforms) cannot resolve focal depth at length scales much smaller than one wavelength because of the interfering nature of waves. Geodetic methods such as INSAR or ground leveling measurement can provide higher resolution focal depths; therefore seismology and geodesy should be combined for future earthquake studies.

\section{Discussion and conclusion}

Both local waveform modeling of $\mathrm{Rg}$ and teleseismic $\mathrm{P}$ waveforms confirm that the Suining-Tongnan earthquake occurred at a shallow depth, probably in the range of $2 \pm 1.5$ $\mathrm{km}$, and definitely less than $4 \mathrm{~km}$. From geological studies, 1D waveform modeling is determined to be appropriate in the study region because of nearly horizontal strata [21,22]. Also, the event is located near wells \#1 and \#2 of the Moxi gas field where well-logging and seismic exploration data can provide detailed information of the geophysical properties of the geological strata. The crystalline basement is well resolved at a depth of $>6 \mathrm{~km}$, and the upper $3 \mathrm{~km}$ of the sediments are Triassic or younger. Moreover, the strata are almost horizontal, without any instances of rigid rock intrusions into the shallow sediments (Figure 5). Therefore, the Suining-Tongnan earthquake should occurr in the Mesozoic sedimentary cover.

Although there are regions on Earth with very shallow earthquakes (e.g. the $0.5 \mathrm{~km}$ deep event in Western Australia [19] and the $2 \mathrm{~km}$ deep Latur earthquake in India [23]), these regions are located on old cratons and the crystalline basement is very shallow. One established case of an earthquake in sediments is the 2003 M4.2 earthquake in Kentucky, but that occurred in Paleozoic strata. There are other reports of M4+ earthquakes in Paleozoic sedimentary rocks [24], but there have been no reported cases of damaging earthquakes $(M 5+)$ in Mesozoic rocks, as far as all the literature that we

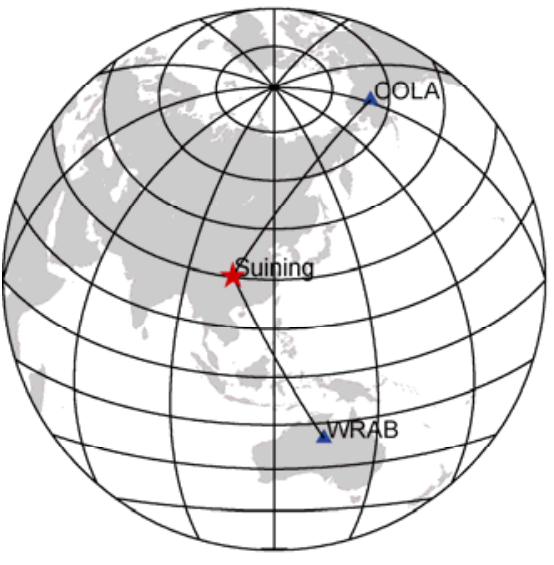

(a)

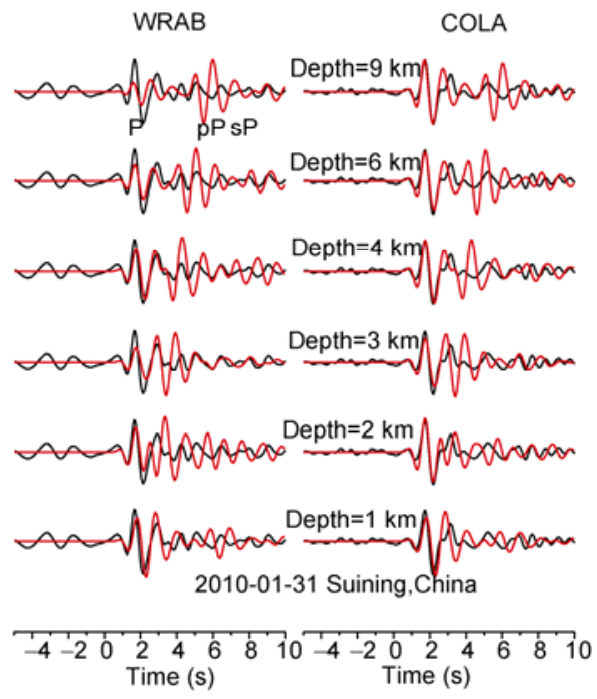

(b)

Figure 4 (a) Suining-Tongnan earthquake (star) and two seismograph stations (triangle); (b) synthetic teleseismic waveforms (red) and observed ones (black) at stations WRAB and COLA for different depths. A depth of $1 \mathrm{~km}$ provides the best waveform fit. 


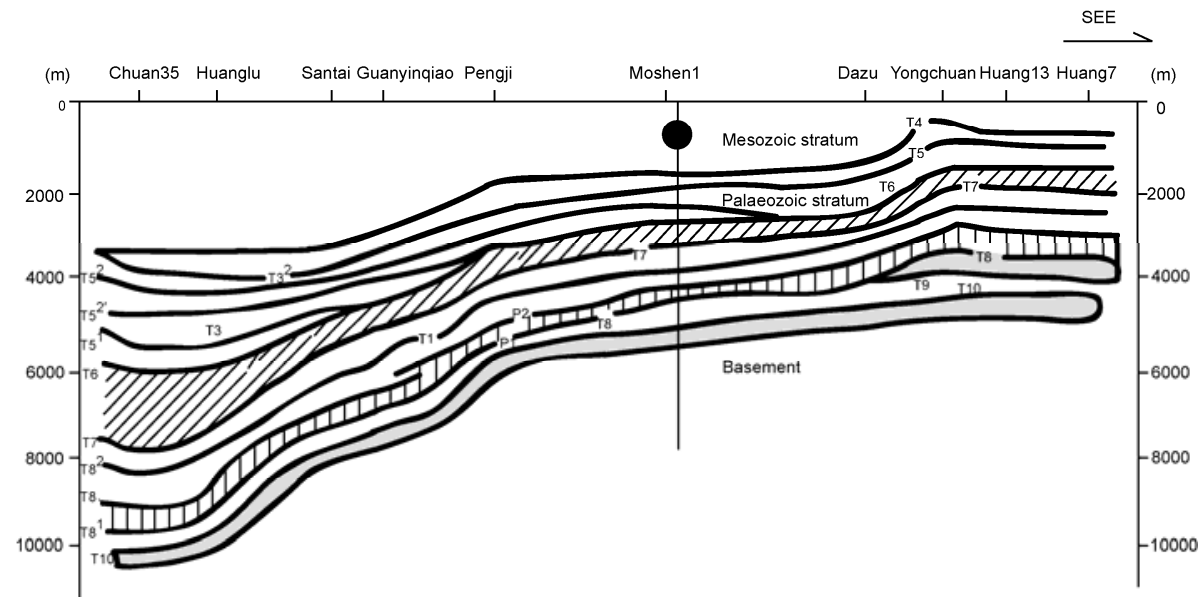

Figure 5 Geological section of the study region [21]. The dot indicates the earthquake hypocenter.

investigated is concerned.

As the top $3 \mathrm{~km}$ of strata in the Suining region is Mesozoic and the porosity has a high fluid content, the rocks should be very weak and are not expected to store sufficient energy to cause damage during release in an earthquake. So, that this M5 earthquake is confirmed to occur in Mesozoic sedimentary cover, is indeed surprising. More puzzling is that no known faults have been found to be associated with the earthquake. Therefore, geophysical researchers are presented with a rare opportunity to study seismogenic processes in weak Mesozoic sediments.

Waveform data were provided by IRIS, the China Earthquake Network Center and the Sichuan Earthquake Network Center. The work was supported by the special fund of the Institute of Earthquake Sciences (02092410) and the Knowledge Innovation Program of the Chinese Academy of Sciences (KZCX2-YW-116).

1 Zhang G M, Wang S Y, Li L, et al. Focal depth of continental earthquakes in China and its seismotectonic implications (in Chinese). Chinese Sci Bull, 2002, 47: 663-668

2 Klose C D, Seeber L. Shallow seismicity in stable continental regions. Seism Res Lett, 2007, 7: 554-562

3 Langston C. Depth of faulting during the 1968 Meckering, Australia, earthquake sequence determined from waveform analysis of local seismograms. J Geophys Res, 1987, 92: 561-574

4 Ma S, Atkinso M G. Focal depths for small to moderate earthquakes $(M \mathrm{n} \geqslant 2.8)$ in western Quebec, Southern Ontario, and Northern New York. Bull Seism Soc Amer, 2006, 96: 609-623

5 Kim Y W, Dineva S, Ma S, et al. The 4 August 2004, Lake Ontario, Earthquake. Seis Res Lett, 2006, 77: 65-73

6 Luo Y, Ni S, Zeng X, et al. Seismological study of an aftershock sequence in the northeastern section of Wenchuan aftershock zone(in Chinese). Sci China Ser D-Earth Sci, 2010, 40: 677-687

7 Horton S P, Kim W Y, Mitch W. The 6 June 2003 Bardwell, Kentucky, Earthquake Sequence: Evidence for a locally perturbed stress field in the Mississippi Embayment. Bull Seism Soc Amer, 2005, 95: $431-445$

8 Mori J. Estimates of velocity structure and source depth using multiple P waves from aftershocks of the 1987 Elmore Ranch and Superstition Hills, California, earthquakes. Bull Seism Soc Amer, 1991, 81: 508-523

9 Kafka A L. Rg as depth discriminant for earthquakes and explosion: A case study in New England. Bull Seisrn Soc Amer, 1990, 80: 373-394

10 Sichuan Geological Survey, Sichuan Regional Geology (in Chinese). Geological Publishing House, Beijing, 1991. 7-263

11 Sichuan Oil and Gas Project. Sichuan Geology of Oil and Gas (in Chinese). Bejing: Oil Industry Press, 1989, 10: 28-74

12 Sun Wei, Liu S, Qin C, et al. Differences of structure and hydrocarbon accumulation characteristics of Middle Triassic Leikoupo Formation between Moxi structure and Longnvsi structure in Central Sichuan, China (in Chinese). J Chengdu Univ Tech, 2009, 36: 654661

13 Saikia C K, Kafka A L, Gnewuch S C, et al. Shear velocity and intrinsic Q structure of the shallow crust in southeastern New England from Rg wave dispersion. J Geophys Res, 1990, 95: 8527-8541

14 Gupta I N, Brunetti J A, Wagner R A, et al. Discrimination between quarry blasts, nuclear explosions and earthquakes. Rep. TGAL-TR84-1, technical report on contract F08606-84-C-0009, TeledyneGeotech, Alexandria, Va., 1984

15 Bennett T J, Barker B W, McLaughlin K L, et al. Regional discrimination of quarry blasts, earthquakes and underground nuclear explosions. S-CUBED report, contract F19628-87-C-0093, AFGL Tech Rep, TR-89-0114, 1989

16 Bath M. Sort-period Rayleigh waves from near-surface events. Phys Earth Planet Inter, 1975, 10: 369-376

17 Saikia C K. Numerical study of quarry generated Rg as a discriminant for earthquakes and explosions: Modeling of $\mathrm{Rg}$ in southwestern New England. J Geophys Res, 1992, 97: 11057-11072

18 Wan K, Ni S, Zhao L. 1D structure in Sichuan Basin from finite frequency whole waveform inversion (in Chinese). In: Proceedings on Wenchuan Earthquake Across-Taiwan-Strait Workshop, 2010

19 Dawson J, Cummins P, Tregoning P, et al. Shallow intraplate earthquakes in Western Australia observed by Interferometric Synthetic Aperture Radar. J Geophys Res, 2008,113, B11408, doi:10.1029/ 2008JB005807

20 Engdahl E R, Hilst R V D, Buland R. Global teleseismic earthquake relocation with improved travel times and procedures for depth determination. Bull Seism Soc Amer, 1998, 88: 722-743

21 Qin Q, Su P, Li D et al., Origin of low structures in central Sichuan area (in Chinese). Xinjiang Petrol Geol, 2005, 26: 108-111

22 Wang Z, Zhao W, Zhang L et al. Geological Strata of Sichuan Basin and Petroloum and Natural Gas exploration (in Chinese). Beijing: Geological Publishing House, 2002

23 Gupta H K, Sarma S V S, Harinarayana T, et al. Fluids below the hypocentral region of Latur Earthquake, India: Geophysical indicators. Geophys Res Lett, 1996, 23:1569-1572

24 Rogers A M, Malkiel A. A study of earthquakes in the Permian Basin of Texas-New Mexico. Bull Seism Soc Amer, 1979, 69: 843-865

Open Access This article is distributed under the terms of the Creative Commons Attribution License which permits any use, distribution, and reproduction in any medium, provided the original author(s) and source are credited. 